\title{
NEUROSCIENCE AND THE 'BEREITSCHAFTSPOTENTIAL': CURRENT DEBATES ABOUT FREE WILL AND AUTONOMY
}

\author{
Christiane Imhof, Heiner Fangerau \\ Institute of the History, Philosophy and Ethics of Medicine, Ulm University, Frauensteige 6, Ulm, D-89075, \\ Germany, E-mail: christiane.imhof@uni-ulm.de, Phone: +49 (0) 731 500-39905
}

The detection of the 'Bereitschaftspotential' by Kornhuber and Deecke stimulated the re-integration of intention and free will into cognitive science. Following research in cognitive neuroscience indicated determinism instead of free will and promoted the reconsideration of philosophical conceptions of mind and brain. With this contribution to the "Memorial-Symposium
Professor Hans Helmut Kornhuber' we give an outline of the reception of the 'Bereitschaftspotential' and the following neuroscientific interpretations of the free will problem. These are contrasted with philosophical conceptions of freedom and with corresponding methodological questions. Finally, a compatibilistic model of freedom is presented. 